archives-ouvertes

\title{
Deciphering the uranium target proteins in human dopaminergic SH-SY5Y cells
}

Claude Vidaud, Mélanie Robert, Eduardo Paredes, Richard Ortega, Emilie

Avazeri, Lun Jing, Jean-Marie Guigonis, Carole Bresson, Veronique Malard

\section{To cite this version:}

Claude Vidaud, Mélanie Robert, Eduardo Paredes, Richard Ortega, Emilie Avazeri, et al.. Deciphering the uranium target proteins in human dopaminergic SH-SY5Y cells. Archives of Toxicology, Springer Verlag, 2019, 93 (8), pp.2141-2154. 10.1007/s00204-019-02497-4 . hal-03066498

\section{HAL Id: hal-03066498 \\ https://hal.archives-ouvertes.fr/hal-03066498}

Submitted on 15 Dec 2020

HAL is a multi-disciplinary open access archive for the deposit and dissemination of scientific research documents, whether they are published or not. The documents may come from teaching and research institutions in France or abroad, or from public or private research centers.
L'archive ouverte pluridisciplinaire HAL, est destinée au dépôt et à la diffusion de documents scientifiques de niveau recherche, publiés ou non, émanant des établissements d'enseignement et de recherche français ou étrangers, des laboratoires publics ou privés. 


\section{DECIPHERING THE URANIUM TARGET PROTEINS IN HUMAN DOPAMINERGIC SH-SY5Y CELLS}

Claude Vidaud ${ }^{1 *}$, Mélanie Robert ${ }^{1}$, Eduardo Paredes ${ }^{2}$, Richard Ortega ${ }^{3,4}$, Emilie Avazeri ${ }^{1}$, Lun Jing ${ }^{5}$, Jean-Marie Guigonis $^{5}$, Carole Bresson ${ }^{2}$ and Véronique Malard ${ }^{6 *}$.

${ }^{1}$ CEA, DRF, Institute of Biosciences and Biotechnologies of Aix Marseille (BIAM), Bagnols-sur-Cèze, France.

${ }^{2}$ Den - Service d'Etudes Analytiques et de Réactivité des Surfaces (SEARS), CEA, Université Paris-Saclay, F91191, Gif sur Yvette, France.

${ }^{3}$ Chemical Imaging and Speciation, CENBG, University of Bordeaux, UMR 5797, 33175 Gradignan, France

${ }^{4}$ CNRS, IN2P3, CENBG, UMR 5797, 33175 Gradignan, France

${ }^{5}$ Laboratory Transporter in Imaging and Radiotherapy in Oncology (TIRO), UMR E4320 CEA - Université Nice Sophia Antipolis, 06107, Nice, France

${ }^{6}$ Laboratory of Protein-Metal Interactions (LIPM), Institute of Biosciences and Biotechnologies of Aix Marseille (BIAM), UMR7265 CEA - CNRS - Aix Marseille Univ, CEA Cadarache, F-13108

*e-mail:

cl_vidaud@hotmail.fr; ORCID ID: 0000-0003-0165-2732, +33-6-88-18-76-61

veronique.malard@cea.fr; ORCID ID: 0000-0002-0020-0518, +33-4-42-25-42-77

The authors declare that they have no conflict of interest.

\section{Acknowledgements}

We acknowledge the Transversal Toxicology Program run by the Direction de la Recherche Fondamentale (DRF) of the Commissariat à l'énergie atomique et aux énergies alternatives (CEA) and the financial support from this program. E.P. also thanks the CEA Enhanced Eurotalents program, co-funded by the European Commission through the Marie Sklodowska-Curie COFUND program under the 7th Framework Program for Research and Technological Development.

This work was also partially funded by the CNRS Interdisciplinary Mission through the PEPS (Projet Exploratoire Premier Soutien) Faidora program (Faibles Doses, Risques, Alertes).

We acknowledge the Li2D laboratory for its technical support. 


\section{Abstract}

Uranium (U) is the heaviest naturally occurring element ubiquitously present in the Earth's crust. Human exposure to low levels of $\mathrm{U}$ is therefore unavoidable. Recently, several studies have clearly pointed out that the brain is a sensitive target for $\mathrm{U}$, but the mechanisms leading to the observed neurological alterations are not fully known.

To deepen our knowledge of the biochemical disturbances resulting from $\mathrm{U}(\mathrm{VI})$ toxicity in neuronal cells, two complementary strategies were set up to identify the proteins that selectively bind $\mathrm{U}(\mathrm{VI})$ in human dopaminergic SH-SY5Y cells. The first strategy relies on the selective capture of proteins capable of binding U(VI), using immobilized metal affinity chromatography, and starting from lysates of cells grown in a U(VI)-free medium. The second strategy is based on the separation of U-enriched protein fractions by size-exclusion chromatography, starting from lysates of U(VI)-exposed cells.

High-resolution mass spectrometry helped us to highlight 269 common proteins identified as the uranoproteome. They were further analyzed to characterize their cellular localization and biological functions. Four canonical pathways, related to the protein ubiquitination system, gluconeogenesis, glycolysis, and the actin cytoskeleton proteins, were particularly emphasized due to their high content of U(VI)-bound proteins. A semiquantification was performed to concentrate on the ten most abundant proteins, whose physico-chemical characteristics were studied in particular depth. The selective interaction of $\mathrm{U}(\mathrm{VI})$ with these proteins is an initial element of proof of the possible metabolic effects of $\mathrm{U}(\mathrm{VI})$ on neuronal cells at the molecular level.

\section{Key words}

Uranium, neurotoxicity, metalloproteins, proteomics, U(VI)-affine proteins, neuronal cells 


\section{Introduction}

The heaviest naturally occurring element, uranium (U), is inherently present in the environment or results from anthropic activities. Natural $\mathrm{U}$ is poorly radioactive, and its chemical toxicity prevails over its radiotoxicity. Under atmospheric conditions and in most environmental systems, the most stable form of $\mathrm{U}$ is the di-oxo cation $\left(\mathrm{U}(\mathrm{VI}) \mathrm{O}_{2}\right)^{2+}$ (uranyl), with $\mathrm{U}$ in the $+\mathrm{VI}$ oxidation state. It is simply referred to as "U(VI)" in the remainder of this article.

In the event of exposure, $\mathrm{U}$ reaches first the blood and then its main target organs, namely the kidneys and the bones, where it accumulates for years while exerting its adverse effects. Less severe effects are, however, observed in the liver, the lungs, and the reproductive and nervous systems (ATSDR 2013; UNSCEAR 2017). Some epidemiological studies have shown behavioral disorders in humans, as well as a correlation between urinary U levels and impaired cognitive test results in veterans of the Gulf War (McDiarmid et al. 2000). Over the last few years, several studies have clearly pointed out that the brain is a sensitive target for $U$ (Dinocourt et al. 2015; UNSCEAR 2017). Exposure to U(VI) induces neurobehavioral changes such as increased locomotor activity, sleep-wake cycle disturbances, decreased memory, and increased anxiety in animal models. The mechanisms by which these neurological alterations are induced are not fully known at the molecular level. Changes in the levels of neurotransmitters and their metabolites involved in acetylcholine and dopaminergic pathways have been observed in animal brains after exposure to U(VI) (Barber et al. 2007; Bensoussan et al. 2009; Bussy et al. 2006). We have recently quantified the expression of dopamine-related genes in the SH-SY5Y cell line, a model of dopaminergic neuronal cells, after their exposure to concentrations of $\mathrm{U}(\mathrm{VI})$ ranging from non-toxic to sub-toxic (Carmona et al. 2018). The expression of the monoamine oxidase B (MAO-B) gene was found to be statistically significantly decreased, while other dopamine-related gene expressions were not modified. These original results suggest that the inhibition of dopamine catabolism, but also that of other MAOB substrates, could constitute selective effects of uranium neurotoxicity. By exposing this cellular model to a non-toxic $\mathrm{U}(\mathrm{VI})$ concentration, we have also revealed the isotopic fractionation of $\mathrm{U}$ during its uptake by the cells, thereby suggesting the existence of a high-affinity transporter protein responsible for $\mathrm{U}(\mathrm{VI})$ uptake (Paredes et al. 2018; Paredes et al. 2016).

In order to improve our general understanding of the metabolic disturbances resulting from U(VI) toxicity in neuronal cells, additional information, such as the identification of the proteins that selectively bind $\mathrm{U}(\mathrm{VI})$ in cellulo (i.e., the "urano-proteome"), is needed. This knowledge is also of key importance for describing the intracellular chemical species of $\mathrm{U}(\mathrm{VI})$, as well as its speciation, because the mechanisms of uptake, metabolism, accumulation, toxicity, and excretion in which an element is involved are highly dependent on the corresponding chemical species and their localization (Michalke et al. 2018; Templeton and Fujishiro 2017). Multidimensional approaches combining chromatographic methods and associated with proteomic studies and metal quantification are powerful methods for deciphering the metalloproteome (Bishop et al. 2018; Szpunar and Lobinski 2002). That said, given the low concentration and complex speciation of metals in biological systems, the screening of their target proteins still remains a challenge, in particular for the actinides, such as $\mathrm{U}(\mathrm{VI})$, because of their noncovalent interactions with proteins. Furthermore, identifying the target proteins within complex protein mixtures from small bio-fluid samples or cell lysates requires selective, low-consumption separation strategies.

The most relevant way to identify the target proteins of $\mathrm{U}(\mathrm{VI})$ is to selectively capture the proteins capable of binding this cation. Chromatographic processes using molecular recognition provide a rational basis for this screening. Such processes have the advantage of providing a relative affinity scale, thereby making it possible to discriminate potential targets from among numerous proteins. Immobilized metal affinity chromatography (IMAC) is a widely accepted technique based on this molecular recognition that is used for enriching natural and recombinant metal targets (Aryal et al. 2012; Porath et al. 1975). A proteomic strategy based on IMAC has previously been implemented to capture and identify proteins with a high affinity for $\mathrm{U}(\mathrm{VI})$, taking into account the physico-chemical properties of $\mathrm{U}(\mathrm{VI})$ and the small amounts of crude human protein extracts generally available for such experiments. To do this, a dedicated U(VI)-loaded support was first specifically designed, and then an IMAC strategy was developed and validated (Basset et al. 2008). This method was successfully applied 
to kidney cell extracts, leading to the identification of U(VI)-affine proteins (Dedieu et al. 2009). In this study, this IMAC method was used to isolate proteins capable of selectively binding U(VI) from SH-SY5Y cell lysates.

Another way to identify the target proteins is to isolate the $\mathrm{U}(\mathrm{VI})$-protein complexes formed in cellulo in response to $\mathrm{U}(\mathrm{VI})$ exposure. To achieve this goal, size-exclusion chromatography (SEC), known for its mild mobile phase conditions and separation process, was selected to fractionate the mixture of free proteins and $\mathrm{U}(\mathrm{VI})$-protein complexes from the extracts of SH-SY5Y cells exposed to U(VI). Size-exclusion chromatography was coupled to quadrupole inductively coupled plasma mass spectrometry (q-ICP-MS) to identify the U-enriched protein fractions and to determine the relative proportion of $\mathrm{U}$ in these fractions.

The originality of the present approach lies in the combination of these two chromatographic strategies to isolate and identify the urano-proteome. The SH-SY5Y cells were first differentiated (Presgraves et al. 2004) to acquire a neuronal dopaminergic phenotype. Next, SEC and IMAC were applied to the protein extracts from these cells grown respectively with and without $\mathrm{U}(\mathrm{VI})$. We were particularly interested in the molecular effects induced by continuous rather than acute $\mathrm{U}(\mathrm{VI})$ exposure. So, to prevent any metabolic disturbance due to toxicity, the cells were submitted to a seven-day period of continuous exposure to a non-toxic $\mathrm{U}(\mathrm{VI})$ concentration $(10 \mu \mathrm{M})$ (Carmona et al. 2018). The proteins from the U-enriched SEC fractions and those selectively captured by IMAC were identified thanks to high-resolution mass spectrometry. The proteins belonging to both populations constitute a part of the urano-proteome, giving more accurate information on the pathways affected in response to a non-toxic $\mathrm{U}(\mathrm{VI})$ exposure. The ten most abundant $\mathrm{U}(\mathrm{VI})$ proteins were characterized with particular attention.

\section{Materials and methods}

All experiments were conducted at room temperature unless otherwise stated. Ultra-pure water $(18 \mathrm{M} \Omega \mathrm{cm}$ at $25^{\circ} \mathrm{C}$ ) was provided by a Milli-Q (Millipore, Billerica, MA, USA) installation. All of the buffers were carefully filtered $(0.22 \mu \mathrm{m})$ and degassed before being used for the chromatographic processes.

\subsection{Materials}

The main reagents and salts were supplied by Sigma-Aldrich Fluka (Saint-Quentin-Fallavier, France).

Protein absorbance was measured on a Varian Cary ${ }^{\circledR} 50$ UV-Vis spectrophotometer (Agilent, Les Ulis, France). Spectra/Por® (Sigma-Aldrich Fluka) membranes (6000-8000) were used for the dialysis. The microcon® centrifugal filters were from Millipore (Molsheim, France).

The HiTrap ${ }^{\circledR}$ DEAE Fast Flow phase $(1 \mathrm{~mL})$ was from GE Healthcare (Vélizy, France). The Duolite ${ }^{\mathrm{TM}} \mathrm{C} 467$ resin was provided by Rohm \& Haas (Philadelphia, PA, USA) and was initially used in its sodium salt form.

Eagle's minimum essential medium (EMEM, ATCC, 30-2003), F12 medium (Life Technologies, 21765-029), fetal bovine serum (FBS, ATCC, 30-2020), and penicillin/streptomycin (Gibco-Thermo Fisher Scientific, 15070063) solutions were used to prepare the culture medium for cell growth and exposure experiments. The culture medium consisted of an equal mix of EMEM and F12 media supplemented with 10\% FBS and 1\% penicillin/streptomycin. TrypLE Express 1X/EDTA (Gibco-Thermo Fisher Scientific, 12605-010) or trypsin 0.25\% EDTA-free (Life Technologies, 25050-014) was used for the trypsinization of the cells. Phosphatebuffered saline (PBS, $\mathrm{pH}$ 7.4) formulated without $\mathrm{CaCl}_{2}$ or $\mathrm{MgCl}_{2}$ (Gibco 10010-015) was used to wash the cells after trypsinization. Retinoic acid (RA) and 12-O-tetradecanoylphorbol-13-acetate (TPA), used for cell differentiation, were purchased from Sigma-Aldrich (R2625 and P8139, respectively). A retinoic acid solution (3 $\mathrm{mg} \mathrm{mL} \mathrm{m}^{-1}$ ) was prepared in sterile dimethyl sulfoxide (DMSO, Sigma-Aldrich) under nitrogen atmosphere in opaque tubes and stored at $-80^{\circ} \mathrm{C}$. Also, TPA was re-suspended at $3 \mathrm{mg} \mathrm{mL}^{-1}$ in sterile DMSO, and the resulting solution was stored at $-20^{\circ} \mathrm{C}$. Plasma Pure Plus $67-70 \% \mathrm{HNO}_{3}$ (SCP Science, Baie-d'Urfé, Canada) was used to prepare the $\mathrm{U}(\mathrm{VI})$ stock solution. $\mathrm{NaHCO}_{3}$ analytical reagent (Normapur grade), anhydrous $\mathrm{Na}_{2} \mathrm{CO}_{3}(99.95 \%$ extrapure, Acros Organics), $\mathrm{NaCl}$ puriss. p.a. (Sigma-Aldrich), and tris(hydroxymethyl)aminomethane (TRIS) 
(ultrapure grade $\geq 99.9 \%$, Sigma-Aldrich) were used to prepare the buffer solution. Ammonium acetate (Normapur grade, VWR Prolabo) was used to prepare the mobile phase for size-exclusion chromatography (SEC) experiments.

\section{2 $\mathrm{U}(\mathrm{VI})$ solution preparation}

Natural uranium powder $\left(\mathrm{U}_{3} \mathrm{O}_{8}\right)$ was produced in-house, and then dissolved in $0.5 \mathrm{M}$ ultrapure $\mathrm{HNO}_{3}$ to prepare a U(VI) stock solution at $151 \mathrm{mM}$.

For the SEC experiments, an intermediate $\mathrm{U}(\mathrm{VI})$ solution $(30 \mathrm{mM}, \mathrm{pH}=8-8.5)$ was extemporaneously prepared (1:5 dilution ratio) by dropwise addition of the $\mathrm{U}(\mathrm{VI})$ stock solution into a buffer made of $0.1 \mathrm{M} \mathrm{NaHCO}_{3}, 0.1 \mathrm{M}$ $\mathrm{Na}_{2} \mathrm{CO}_{3}, 0.15 \mathrm{M} \mathrm{NaCl}$, and $0.05 \mathrm{M}$ TRIS, in order to prevent $\mathrm{U}(\mathrm{VI})$ precipitation. The $10 \mu \mathrm{M}$ exposure solution was then obtained by extemporaneous dilution of the intermediate solution in the culture medium.

For the IMAC experiments, the U(VI)-loaded beads were prepared according to operating conditions published elsewhere (Basset et al. 2008). Briefly, the $151 \mathrm{mM} \mathrm{U}(\mathrm{VI})$ stock solution was diluted in $50 \mathrm{mM}$ ammonium acetate buffer ( $\mathrm{pH} 4.0)$ to ensure $0.7 \mathrm{mM} \mathrm{U}(\mathrm{VI})$ per $\mathrm{mL}$ of beads. After the beads were preconditioned in $50 \mathrm{mM}$ ammonium acetate buffer at $\mathrm{pH} 4.0$, they were left in contact with this $\mathrm{U}(\mathrm{VI})$ solution overnight at $4^{\circ} \mathrm{C}$ under gentle stirring, and then stored at $4^{\circ} \mathrm{C}$ until use.

\subsection{SH-SY5Y cell culture, differentiation, and exposure to $\mathrm{U}(\mathrm{VI})$}

Commercial human SH-SY5Y (ATCC, CRL-2266, batch 59740436) cells were differentiated into neuron-like cells prior to $\mathrm{U}(\mathrm{VI})$ exposure experiments. Cells were grown in $175 \mathrm{~cm}^{2}$ flasks at $37^{\circ} \mathrm{C}$ in $5 \% \mathrm{CO}_{2}$ for ten days. The culture medium was replaced with fresh medium every three or four days. Afterward, the cells were passaged by trypsinization using TrypLE Express 1 X/EDTA and then seeded at 25,000 cells $\mathrm{cm}^{-2}$. They were differentiated into neuron-like cells according to the method described by Presgraves et al. (Presgraves et al. 2004). Briefly, the culture medium was replaced with fresh medium containing $10 \mu \mathrm{M} \mathrm{RA}$, and the cells were incubated for 3.5 days. The culture medium was then replaced with fresh medium containing $80 \mathrm{nM}$ TPA and left for an additional 3.5 days to obtain differentiated cells. The dopaminergic phenotype in SH-SY5Y human cells was verified by phase-contrast microscopy to check for neural differentiation and by western blot analysis for tyrosine hydroxylase expression (Carmona et al. 2018).

For the IMAC strategy, the cells were cultured for seven days in U(VI)-free medium.

For the SEC strategy, the cells were exposed for seven days to a freshly prepared $10 \mu \mathrm{M} \mathrm{U}(\mathrm{VI})$ solution as described above. This U(VI) solution was replaced once three days after exposure began. The cells were then trypsinized using an EDTA-free trypsin, collected, and washed twice with PBS. The cell pellets were stored at $-80{ }^{\circ} \mathrm{C}$ until use.

\subsection{Soluble protein extraction and sample preparation for chromatography}

The cells were suspended at $30 \times 10^{6}$ cells per $\mathrm{mL}$ in $0.02 \mathrm{M}$ TRIS $\mathrm{pH} 7.5$ containing anti-proteases (Roche cocktail, EDTA-free) and $0.002 \mathrm{M}$ spermine base (Sigma). The cells were disrupted by one shot at $1000 \mathrm{bar}$ using a cell disruption system (Constant Systems, Northants, UK), then incubated for $30 \mathrm{~min}$ at $4{ }^{\circ} \mathrm{C}$. The extracts were then ultra-centrifuged $(1 \mathrm{~h}$ at $100000 \mathrm{~g})$ and the supernatants collected. Aliquots were stored at $-20^{\circ} \mathrm{C}$ until use.

\subsection{Ion exchange and IMAC}

\subsubsection{Ion exchange}

A first ion exchange chromatography purification step (Dedieu et al. 2009) was performed with an Åkta Purifier 10 System (GE Healthcare, Uppsala, Sweden) equipped with on-line UV detection. Protein samples from cell extracts were dialyzed (overnight at $4^{\circ} \mathrm{C}$ ) against $0.02 \mathrm{M}$ HEPES buffer. Because of their tendency to precipitate in this buffer regardless of $\mathrm{pH}$ (8.0 or 7.4), the samples were ultra-filtered (Microcon, $3000 \mathrm{Da}$, Millipore) for 10 $\mathrm{min}$ at $10000 \mathrm{~g}$ before use. The aliquots from these protein samples $\left(2 \mathrm{~mL}\right.$ at $\left.\sim 660 \mu \mathrm{g} \mathrm{mL} \mathrm{L}^{-1}\right)$ were injected onto a $1 \mathrm{~mL}$ HiTrap DEAE Fast Flow column $\left(0.2 \mathrm{~mL} \mathrm{~min}^{-1}\right.$ flow rate). Reproducible processes led to similar chromatograms regardless of $\mathrm{pH}$ (8.0 or 7.4), and $\mathrm{pH} 7.4$ was selected. The flow-through fraction (A1) was collected. Then, the ionic strength was linearly increased up to $0.5 \mathrm{M} \mathrm{NaCl}$, leading to the collection of two other 
populations (A2 and A3). No protein was then eluted with buffer above $0.5 \mathrm{M}$ and up to $1 \mathrm{M} \mathrm{NaCl}$. The UV absorbance $(\lambda=260$ and $280 \mathrm{~nm})$ and the protein content (BCA assay) were checked for A1, A2 and A3.

\subsubsection{Protein capture by IMAC}

$\mathrm{U}(\mathrm{VI})$-free and U(VI)-loaded Duolite C467 beads were prepared as previously described (Basset et al. 2008). The batch conditions were chosen because of the small bead volume used. Before each experiment, $50 \mu \mathrm{L}$ of $\mathrm{U}(\mathrm{VI})$-free and $\mathrm{U}(\mathrm{VI})$-loaded beads were conditioned by rinsing six times with $0.05 \mathrm{M}$ HEPES, $0.5 \mathrm{M} \mathrm{NaCl} \mathrm{pH}$ 7.4 buffer plus $0.05 \%$ Brij as surfactant (binding buffer). A high $\mathrm{NaCl}$ concentration prevents ion exchange with $\mathrm{U}(\mathrm{VI})$-loaded beads, and the Brij surfactant enables or strongly limits hydrophobic interactions with the support (Basset et al. 2008; Dedieu et al. 2009).

In parallel, the three fractions collected (A1, A2, A3) from the ion exchange chromatography were first extensively dialyzed overnight against the binding buffer. Aliquots of these fractions were then adjusted to a protein concentration around $60 \mu \mathrm{g} \cdot \mathrm{mL}^{-1}$, and then $0.2 \mathrm{M} \mathrm{NaHCO}_{3}(5 \mu \mathrm{L}$ per $\mathrm{mL})$ was added. A sample of each fraction $(1 \mathrm{~mL})$ was placed in contact with $50 \mu \mathrm{L}$ of the conditioned $\mathrm{U}(\mathrm{VI})$-loaded and $\mathrm{U}(\mathrm{VI})$-free beads (room temperature, gentle stirring for $60 \mathrm{~min})$. The supernatants were discarded. The U(VI)-loaded and U(VI)-free beads were washed seven times with $1 \mathrm{~mL}$ of the binding buffer and dialyzed overnight at $4^{\circ} \mathrm{C}$ against the same buffer to ensure the elimination of all proteins non-specifically bound to the beads. Then, the proteins specifically bound to the $\mathrm{U}(\mathrm{VI})$-loaded and $\mathrm{U}(\mathrm{VI})$-free beads (control fractions) were recovered separately by bringing the beads into contact with $500 \mu \mathrm{L}$ of a $0.2 \mathrm{M}$ sodium carbonate solution for $90 \mathrm{~min}$. The beads were discarded, and the protein solutions were desalted in ammonium carbonate by eight successive concentrationdilution steps in micro-concentrator systems at $8^{\circ} \mathrm{C}$ and $13000 \mathrm{~g}$ (Microcon, $3000 \mathrm{Da}$, Millipore) to reach volumes of $\sim 90-120 \mu \mathrm{L}$. The proteins potentially found in the control fractions reflect non-specific interactions with the support and were not considered further for the proteomic study.

\subsection{Size-exclusion chromatography (SEC) coupled to inductively coupled plasma mass spectrometry (ICP-MS)}

A Smartline chromatographic system (KNAUER, Berlin, Germany) was used. The column was a $4.6 \mathrm{x} 150 \mathrm{~mm}$ BEH 200 (Waters, Milford, USA) with $1.7 \mu \mathrm{m}$ particle size and $200 \AA$ A pore size. The mobile phase was made of $100 \mathrm{mM}$ ammonium acetate in ultrapure water, and the flow rate was $0.3 \mathrm{~mL} \cdot \mathrm{min}^{-1}$ (dual Pump 1000). To estimate the molecular weight range of the eluted populations of proteins, the column was calibrated before use using $100 \mathrm{ppm}$ gel filtration standard proteins (Bio-Rad, Marnes-la-Coquette, France) : thyroglobulin $(\approx 670$ $\mathrm{kDa})$, ferritin $(\approx 440 \mathrm{kDa})$, anti-IgE $(\approx 150 \mathrm{kDa})$, ovotransferrin $(\approx 75 \mathrm{kDa})$, ovalbumin $(\approx 43 \mathrm{kDa})$, and aprotinin $(\approx 6.5 \mathrm{kDa})$.

Cell lysates $(20 \mu \mathrm{L})$ were manually injected into the column using a Rheodyne injector valve (model 9725), with monitoring of the UV signal at $\lambda=280 \mathrm{~nm}$ (Smartline PDA detector 2800). For the detection of the protein fractions containing uranium, the UV detector was connected in series to a quadrupole ICP-MS (q-ICP-MS, X7, Thermo Fisher Scientific) using PEEK tubing (i.d. $125 \mu \mathrm{m}$ ), with the ${ }^{238} \mathrm{U}^{+}$signal being monitored. The integration time per chromatographic point with q-ICP-MS was $10 \mathrm{~ms}$, and approximately 5800 points were acquired for a run time of $10 \mathrm{~min}$

The three main protein fractions enriched in U(VI) (denoted F1, F2, F3) were identified and collected separately.

\subsection{High-resolution electrospray ionization mass spectrometry (HR ESI-MS)}

Proteins were first extracted using trichloroacetic acid (TCA, final concentration 10\%). Pellets were mixed with $30 \mu \mathrm{L}$ of Laemmli LDS buffer (Invitrogen). Samples were heated at $99^{\circ} \mathrm{C}$ for 5 min and loaded $(30 \mu \mathrm{L}$ per well) onto a NuPAGE 4-12\% Bis-Tris gel (Invitrogen). They were subjected to a short denaturing electrophoresis migration (5 min) at $200 \mathrm{~V}$ in MES SDS $1 \times$ running buffer. The polyacrylamide band containing the entire LDSsoluble proteome was processed for an in-gel trypsin digestion using sequencing-grade trypsin (Promega, Charbonnières-les-Bains, France) and ProteaseMAX Surfactant (Promega) at $0.01 \%$. 
The resulting peptides $(10 \mu \mathrm{L})$ were analyzed using either an ESI-Q Exactive HF mass spectrometer (Thermo Fisher Scientific) incorporating an ultra-high-field Orbitrap analyzer and coupled to an Ultimate 3000 RSL Nano LC System (Dionex-LC Packings) for IMAC fractions, or an Ultimate 3000 RSL Capillary LC System (Thermo Fisher Scientific) for SEC fractions.

For nano-liquid chromatography, the samples were loaded and desalted on-line on a reversed-phase Acclaim PepMap100 C18 micro precolumn ( $5 \mu \mathrm{m}, 100 \AA, 300 \mu \mathrm{m}$ internal diameter x $5 \mathrm{~mm}$, Thermo Fisher Scientific) and separated on an Acclaim PepMap100 C18 nano column $(3 \mu \mathrm{m}, 100 \AA, 75 \mu \mathrm{m}$ internal diameter x $50 \mathrm{~cm}$, Thermo Fisher Scientific) at a $0.3 \mu \mathrm{L} / \mathrm{min}$ flow rate for $60 \mathrm{~min}$ with a $2.5-40 \%$ gradient of solvent B $(80 \%$ acetonitrile, $20 \%$ water, $0.1 \%$ formic acid) against solvent $\mathrm{A}$ ( $0.1 \%$ formic acid, $99.9 \%$ water). A top 20 datadependent method was used for MS/MS spectrum acquisition. Full-scan mass spectra were recorded from 350 to $1500 \mathrm{~m} / \mathrm{z}$ with an automatic gain control target set at $3 \times 10^{6}$ ions and a resolution of 60000 . Each MS/MS scan was initiated at a resolution of 15000 for ions with potential charge of 2+ and 3+ and with a dynamic exclusion of $10 \mathrm{~s}$. The MS/MS spectra were recorded with an automatic gain control target set at $1 \times 10^{5}$ ions.

For capillary liquid chromatography, the system was set up for pre-concentration mode using a $300 \mu \mathrm{m}$ x $5 \mathrm{~mm}$ trap column in back-flush configuration at $40^{\circ} \mathrm{C}$ (P/N 6720.0315). An EASY-Spray $15 \mathrm{~cm}$ x $150 \mu \mathrm{m}$ column (P/N ES806) was connected to the system and coupled to the system with an EASY-Spray source (P/N ES081) operating at $40^{\circ} \mathrm{C}$. The flow rate was $1.2 \mu \mathrm{L} / \mathrm{min}$ with a $5-45 \%$ gradient of solvent B (80\% acetonitrile, $20 \%$ water, $0.1 \%$ formic acid) against solvent $\mathrm{A}(0.1 \%$ formic acid, $99.9 \%$ water) for $180 \mathrm{~min}$. A top 15 datadependent method was used for MS/MS spectrum acquisition. Full-scan mass spectra were registered from 350 to $1500 \mathrm{~m} / \mathrm{z}$ with an automatic gain control target set at $3 \times 10^{6}$ ions and a resolution of 70000 . Each MS/MS scan was initiated at a resolution of 17500 for ions with potential charge of $2+, 3+$, and $4+$ and with a dynamic exclusion of $20 \mathrm{~s}$. The MS/MS spectra were recorded with an automatic gain control target set at $5 \times 10^{4}$ ions.

\subsection{Proteomic data analysis}

All MS raw data files were analyzed by Proteome Discoverer software 2.1.1.21 (Thermo Fisher Scientific, France) using the Sequest HT search engine against a database of protein sequences (UniProt database release 2015_2). The XCorr confidence threshold was maintained above 0.7 for all parameters. Precursor mass tolerance was set to $10 \mathrm{ppm}$, and fragment ion tolerance was $0.02 \mathrm{Da}$, with permission for two missed cleavages in the trypsin digests. A decoy database search strategy was also used to estimate the false discovery rate (FDR) for ensuring the reliability of the proteins identified: a $1 \%$ target FDR was the strict criterion and a 5\% target FDR was the relaxed criterion using Percolator; also, at least two peptides were required to match a protein entry in view of its identification. The strict maximum parsimony principle was applied, and only peptide spectra with at least medium confidence were considered for protein grouping. Carbamidomethylation on cysteine was set as a static modification and oxidation of methionine as a dynamic modification. For relative quantitation, both unique and razor peptides were considered a highly confident identification and used for quantification. Reporter ion abundances were corrected for isotopic impurities based on the manufacturer's data sheets. Signal-to-noise ratio $(\mathrm{S} / \mathrm{N})$ values were used to represent the reporter ion abundance and an average reporter $\mathrm{S} / \mathrm{N}$ threshold of 10 and above were required for quantitation spectra. The $\mathrm{S} / \mathrm{N}$ values of the peptides, which were summed from the $\mathrm{S} / \mathrm{N}$ values of the identified peptide sequences (PSMs), represent the abundance of the proteins. The number of PSM's is the total number of identified peptide spectra matched for the protein.

The number of peptides per protein was determined for each sample. The relative quantitative proteomic analysis was calculated according to the method of normalized spectral abundance factors (NSAF) (Zybailov et al. 2006). The normalized spectral abundance factor is a ratio calculated by normalizing the peptide numbers obtained for a protein (i) by the respective molecular weight (MW) as follows:

$$
\operatorname{NSAFi}(\%)=\left(\frac{\frac{S C i}{M W_{i}}}{\sum_{i=1}^{n}\left(\frac{S C i}{M W_{i}}\right)}\right) \times 100
$$




\subsection{Integrative biological analysis}

The lists of proteins of interest obtained from the two analytical strategies were concatenated and the duplicates removed. A Venn diagram was built in order to determine the population of proteins common to both pools (urano-proteome).

The list of the common proteins obtained after Venn analysis was uploaded into Ingenuity Pathway Analysis (IPA) software (QIAGEN) for biological analysis. This data set was processed to investigate gene functional annotation and distribution into known cell functions and canonical pathways, according to the IPA knowledge database. Associations with known canonical pathways were expressed by ratios (in percentage), meaning the number of proteins that belong to a canonical pathway divided by the total number of known proteins mapping this pathway. The significance of highlighted functions and pathways was calculated using a Fisher's exact test with a p-value set at 0.05 .

\section{Results}

\subsection{Study design}

We chose two complementary analytical strategies to collect and identify the proteins capable of binding $\mathrm{U}(\mathrm{VI})$ in cellulo. Human dopaminergic SH-SY5Y cells were cultured in a U(VI)-free medium or exposed to a non-toxic concentration $(10 \mu \mathrm{M})$ of $\mathrm{U}(\mathrm{VI})$ for seven days (Carmona et al. 2018). The IMAC approach relies on selective protein capture from lysates of cells grown in a $\mathrm{U}(\mathrm{VI})$-free medium, leading to the direct identification of $\mathrm{U}(\mathrm{VI})$ affine proteins. The SEC strategy consists in a fractionation of lysates of cells exposed to U(VI) to collect protein fractions enriched in $\mathrm{U}$. The protein fractions obtained from SEC experiments should contain both free proteins and $\mathrm{U}(\mathrm{VI})$-protein complexes. The proteins common to both strategies, identified using nano-liquid chromatography coupled to high-resolution electrospray ionization tandem mass spectrometry (nano-LC-HR ESI-MS/MS), are referred to herein as the urano-proteome. The experimental design is depicted in Figure 1.

\subsection{Proteins captured by IMAC on U(VI)-loaded and U(VI)-free beads}

An initial ion exchange chromatography step was performed to fractionate the protein samples and eliminate some residual DNA (Dedieu et al. 2009). When the protein sample $\left(2 \mathrm{~mL}, 660 \mu \mathrm{g} \mathrm{mL}^{-1}\right)$ was injected onto the column, a flow-through fraction (denoted A1) was first eluted, followed next by a large A2 fraction in the first third of the $\mathrm{NaCl}$ gradient and finally by a narrow $\mathrm{A} 3$ fraction in the last third of the $\mathrm{NaCl}$ gradient. The protein contents in these A1, A2 and A3 fractions were in the range of around 180, 718, and $110 \mu \mathrm{g}$, respectively, and the protein recovery was around $76 \%$. Half of each of these three fractions was then placed in contact with the $\mathrm{U}(\mathrm{VI})$-loaded beads, while in parallel the other half was placed in contact with the U(VI)-free beads to serve as the control. All of the specifically captured proteins obtained from these six IMAC experiments were submitted to nano-LC-HR ESI-MS/MS analysis for identification. The few proteins eluted from U(VI)-free beads but also present in the populations eluted from $\mathrm{U}(\mathrm{VI})$-loaded beads were not considered as $\mathrm{U}(\mathrm{VI})$-affine proteins.

\subsection{U(VI)-containing protein fractions obtained by SEC}

There is very little knowledge concerning cytosolic U(VI)-bound proteins in any type of cell (Dedieu et al. 2009). The bonds between proteins and U(VI) are often weak and labile because they are ionic and generally solvent-exposed (Pible et al. 2006). Therefore, the SEC method was selected for the fractionation of the mixture of proteins from the extracts of SH-SY5Y cells exposed to $\mathrm{U}(\mathrm{VI})$. For the fractionation to be as efficient as possible while maintaining the best possible integrity of the U(VI)-protein complexes, we selected a lastgeneration stationary phase packed with bridged-ethylene hybrid inorganic-organic (BEH) support material of less than $2 \mu \mathrm{m}$ in particle diameter. Figure 2 shows the chromatograms monitored by UV detection as well as by q-ICP-MS following the ${ }^{238} \mathrm{U}^{+}$signal. Under our experimental conditions, the proteins were eluted in less than eight minutes. The UV elution profile shows the distribution of proteins with apparent molecular weights ranging from $600 \mathrm{kDa}$ to $3 \mathrm{kDa}$ according to the calibration curve, reflecting the complexity of this protein sample. 
The ICP-MS elution profile shows the presence of $\mathrm{U}$ among the entire protein population, but distributed in three main peaks that were collected and denoted as fractions F1, F2 and F3. Around $50 \%$ of the U(VI) was quantified in the F2 fraction, whereas the F1 and F3 fractions accounted for $40 \%$ and 10\%, respectively. Given the SEC separation mode and the fractionation range of the selected phase, the complexes of U(VI) with small ligands are eluted last. So we can assume that the U(VI) found in these three fractions is present in the form of U(VI)-bound proteins. The final protein peak, eluted after seven minutes, did not contain a significant amount of U(VI) and was not considered in our study. Therefore, so as not to discard any of the U(VI)-bound proteins, these three fractions - F1, F2 and F3 - were subjected to proteomic analysis.

\subsection{Proteomic analysis}

The proteins from all nine samples obtained with both analytical techniques (A1, A2, A3 eluted from U(VI)loaded beads; A1, A2, A3 eluted from U(VI)-free beads for IMAC; and F1, F2, F3 for SEC) were analyzed separately using nano-liquid chromatography coupled to high-resolution electrospray ionization tandem mass spectrometry (nano-LC-HR ESI-MS/MS).

Using the IMAC strategy, 433 different proteins were selected using the criteria indicated in the Materials and methods section. First of all, only 14 proteins were isolated from the U(VI)-free beads used for the IMAC control: we located six human keratins in the three A1, A2 and A3 control fractions, endoplasmin and cytoplasmic actin G1 in the A1 control fraction, $10-\mathrm{kDa}$ heat shock protein in the A2 control fraction, and peptidylprolyltransisomerase FKBP2 in the A3 control fraction. Apart from human keratins, which are often found as an experimental contaminant in such analyses, the four other proteins can be non-specifically bound to the matrix of the beads. They represent around $1 \%$ of the proteins captured on the U(VI)-loaded beads. They were eliminated from the protein list of the IMAC strategy and not considered in our proteomic analysis. The detailed results for the identification of the 433 proteins are given in Table S1.

The F1, F2 and F3 fractions from the SEC strategy led to the identification of 1257 proteins (Table S2). This difference between the 433 proteins captured by IMAC and the 1257 proteins from the SEC experiment is not surprising, since in the SEC process, free and U(VI)-bound proteins can be eluted in the same fraction, according to their molecular size.

\subsubsection{Identification of the common IMAC and SEC protein population}

The protein lists obtained from the two chromatographic strategies were concatenated (Table S3). A Venn diagram analysis was performed, leading to 269 proteins common to the two methods (Fig. 3). Because these 269 proteins are both affine for $\mathrm{U}(\mathrm{VI})$ and also present in $\mathrm{U}(\mathrm{VI})$-rich protein fractions, we can reasonably assume that these are the $\mathrm{U}(\mathrm{VI})$-bound proteins present in the SEC fractions. So, $62 \%$ of the proteins captured by IMAC (269/433) and $21 \%$ of the proteins isolated by SEC (269/1257) belong to the urano-proteome pool.

In a previous study using the same IMAC methodology, $64 \mathrm{U}(\mathrm{VI})$-affine proteins were identified from human kidney-2 cell extracts (Dedieu et al. 2009). The proteomic tools and techniques have progressed considerably over the past ten years, making it possible to identify increased numbers of proteins with a high confidence level. These 64 proteins, however, were compared to the 269 common proteins. Forty-two out of the 64 proteins $(65 \%)$ are present among the 269 currently selected proteins. Interestingly, and despite the fact that both the cell lines and the proteomic tools used are different, the population of proteins overlapping these two lists is considerable, thereby validating these targets. Concerning SEC, 162 proteins out of $269(60 \%)$ and 96 proteins out of 269 (36\%) belonged to the F1 and F2 fractions, respectively, and accounted for $90 \%$ of the uranium. The last F3 fraction contained only 11 of these 269 proteins (4\%). These results are consistent with both the absorbance and $\mathrm{U}(\mathrm{VI})$-content profiles registered during the SEC process.

\subsubsection{Cellular localization and biological function of the urano-proteome}

The urano-proteome was further analyzed to identify the cellular localization, biological function and metabolic pathways that contain a high proportion of $\mathrm{U}(\mathrm{VI})$-bound proteins. The localization and the biological functions 
of the 269 common proteins were predicted with the IPA software (Table S4). The distribution of these proteins, shown in Figure 4, is as follows: $70 \%$ are found in the cytoplasm, $18 \%$ in the nucleus, $4 \%$ in the extracellular space and $6 \%$ in the plasma membrane. A very gentle method of mechanical cell lysis was selected in order to preserve the integrity of the $\mathrm{U}(\mathrm{VI})$ complexes as much as possible, and a detergent-free buffer was used. Using in situ cellular chemical mapping, we have observed that $\mathrm{U}$ distribution is mainly cytoplasmic for the same cellular model and exposure conditions (Carmona, 2018). We have also previously shown that 2.5 times fewer proteins are recovered by mechanical lysis compared to chemical lysis; the main proteins affected are membrane proteins and large complexes that are solubilized only in the presence of a detergent (Malard et al. 2005). It is also interesting to note that 49 nuclear proteins could be obtained by mechanical lysis of the nuclei (Table S4). In particular, the urano-proteome contains six ribonucleoproteins (hnRNPs). The hnRNPs are multifunctional RNAbinding proteins involved in processing heterogeneous nuclear RNAs into mature mRNAs and acting as trans factors in regulating gene expression (Chaudhury et al. 2010). The hnRNPs undergo nucleocytoplasmic shuttling, transporting mRNA out of the nucleus. They are also essential for the numerous cytoplasmic functions (Han et al. 2010). Twenty-one transcription or translation regulator proteins were also found. Although most of the urano-proteome consists of cytoplasmic proteins, these results also suggest that $\mathrm{U}(\mathrm{VI})$ interacts with proteins involved in gene expression regulation.

The analysis of the biological function of the 269 common proteins also shows that the urano-proteome contains mainly enzymes (42\%) (Fig. 4). Although these data are not direct evidence of the possible metabolic effects of $\mathrm{U}(\mathrm{VI})$ on cells, a selective binding of $\mathrm{U}(\mathrm{VI})$ to these proteins indicates possible modes of action of $\mathrm{U}(\mathrm{VI})$ on cellular metabolism.

\subsubsection{Pathway analysis}

To go further in this analysis, the main canonical pathways along with the main diseases and functions were determined using IPA (Table 1 and Table S4). The most highly altered canonical pathways were related to the protein ubiquitination system, gluconeogenesis, glycolysis, and actin cytoskeleton protein in terms of the number of proteins found in the urano-proteome in comparison with the total number of proteins in each pathway, expressed in percentage form.

Table 1: Top five canonical pathways and top five diseases associated with the urano-proteome, as analyzed by IPA. Names are ordered according to $p$-value $(\mathrm{p}<0.05)$. The ratio value is also shown, as is the number of proteins implicated.

\begin{tabular}{|c|c|c|}
\hline \multicolumn{3}{|l|}{ Top Canonical Pathways } \\
\hline Name & p-value & Overlap \\
\hline Protein Ubiquitination Pathway & $1.45 \mathrm{E}-19$ & $10.9 \% \quad 29 / 265$ \\
\hline Gluconeogenesis I & 7.07E-19 & $50.0 \% 13 / 26$ \\
\hline Glycolysis I & $2.31 \mathrm{E}-13$ & $38.5 \% \quad 10 / 26$ \\
\hline Actin Cytoskeleton Signaling & $3.87 \mathrm{E}-06$ & $5.7 \% \quad 13 / 227$ \\
\hline Unfolded protein response & 4.07E-06 & $12.7 \% 7 / 55$ \\
\hline \multicolumn{3}{|l|}{ Top Diseases and Bio Functions } \\
\hline \multicolumn{3}{|l|}{ Diseases and Disorders } \\
\hline Name & $\mathrm{p}$-value & \#Molecules \\
\hline Endocrine System Disorders & $4.98 \mathrm{E}-04-1.03 \mathrm{E}-17$ & 38 \\
\hline Organismal Injury and Abnormalities & $5.82 \mathrm{E}-04-1.03 \mathrm{E}-17$ & 256 \\
\hline Neurological Disease & $5.62 \mathrm{E}-04-8.56 \mathrm{E}-17$ & 113 \\
\hline Skeletal and Muscular Disorders & $4.26 \mathrm{E}-04-8.56 \mathrm{E}-17$ & 96 \\
\hline Psychological Disorders & $5.76 \mathrm{E}-07-2.54 \mathrm{E}-16$ & 68 \\
\hline
\end{tabular}

Gluconeogenesis and glycolysis

The highest percentage is observed for gluconeogenesis with 13 proteins (50\%), followed by glycolysis with ten proteins (38.5\%, including isoforms). The role of glucose in physiological and pathological brain function was reviewed a few years ago (Mergenthaler et al. 2013). The mammalian brain is the main consumer of glucose, 
because glucose is its main source of energy. Its metabolism provides the fuel for physiological brain function through the generation of ATP, the foundation for neuronal and non-neuronal cellular maintenance, as well as the generation of neurotransmitters. Therefore, tight regulation of glucose metabolism is critical for brain physiology, and disturbed glucose metabolism in the brain underlies several diseases affecting the brain (Mergenthaler et al. 2013). In this context, it is very interesting to see that seven of the nine glycolysis enzymes belong to the urano-proteome (see Fig. 5). We can also notice that these proteins are found in SEC fraction F2, which contains the highest amount of $\mathrm{U}(\mathrm{VI})$.

In the gluconeogenesis pathway, many steps are the opposite of those found in glycolysis. This is why both pathways are found in the main canonical pathways. Of the 13 enzymes of gluconeogenesis found in the uranoproteome (IPA analysis), nine are common to those of glycolysis. The four others are specific to gluconeogenesis and concern the transport of oxaloacetate and malate from the mitochondria to the cytosol (MDH1 and MDH2); the oxidative decarboxylation of malate to pyruvate (ME2: NAD-dependent malic enzyme); and ME1 (malic enzyme 1), which links the glycolytic and citric acid cycles through the reversible oxidative decarboxylation of malate. The effect of uranyl nitrate on enzymes of carbohydrate metabolism has been studied in kidneys of rodents exposed in vivo to natural $\mathrm{U}(\mathrm{VI})$. The activity of lactate dehydrogenase increased, whereas the activities of isocitrate, succinate and malate dehydrogenases, glucose-6-phosphatase, and fructose-1,6-bisphosphatase significantly decreased following natural U(VI) exposure (Banday et al. 2008). In another study, the effect of uranyl nitrate has been investigated in isolated human and mouse kidney cortex tubules metabolizing the physiological substrate lactate. Uranyl nitrate in the millimolar range reduced lactate removal and gluconeogenesis in a concentration-dependent fashion: lactate dehydrogenase, pyruvate carboxylase, phosphoenolpyruvate carboxykinase, and glucose-6-phosphatase fluxes were lowered by 20 to $45 \%$ (Renault et al. 2010). Our present results show that U(VI) could have an impact on both pathways through its binding with enzymes belonging to both pathways. They are in agreement with studies demonstrating that uranium affects the activity of these enzymes. It is nevertheless necessary to mention that in brain metabolism, gluconeogenesis is a very minor pathway, with most of the glucose supplied to the brain being provided by the blood. Interestingly, disturbed glucose metabolism can be the foundation for the development of a wide variety of disorders in the brain, particularly neurodegenerative diseases (Mergenthaler et al. 2013).

\section{Proteasome}

Twenty-nine proteins out of the 265 in the protein ubiquitination pathway are found in the urano-proteome (Table 1). Using tandem mass spectrometry, Tai et al. (Tai et al. 2010) identified 30 proteins of the brain $26 \mathrm{~S}$ proteasome. Strikingly, five out of the seven proteins from proteasome subunits alpha described in this paper and six out of seven proteins from proteasome subunits beta belong to the urano-proteome. These findings highlight our previous results with regard to evaluating the response of a human lung cell line (A549) to U(VI) by a proteomic approach. Uranyl treatment triggered differential expression of 14 proteins identified as ubiquitinylated fragments of cytokeratin 8 and cytokeratin 18 . We hypothesized that $\mathrm{U}(\mathrm{VI})$ could cause an abnormality in the ubiquitin degradation system that may lead to an accumulation of cytokeratin degradation products in $\mathrm{U}(\mathrm{VI})$-exposed cells (Malard et al. 2005). The binding of $\mathrm{U}(\mathrm{VI})$ to many of the proteins in the $26 \mathrm{~S}$ subunit of the proteasome could explain these results obtained previously.

Actin cytoskeleton pathway

Thirteen proteins from the actin cytoskeleton pathway were found in the urano-proteome, among them cytoplasmic beta-actin itself. Again, in a previous study, we demonstrated that the expression of genes and proteins coding for actin and tubulin was down-regulated in human renal cells upon exposure to uranium (Prat et al. 2005). Actin was also recently demonstrated to bind $\mathrm{U}(\mathrm{VI})$, identifying this protein as a potential uranyl target in a zebrafish model (Eb-Levadoux et al. 2017).

Actin is a highly conserved cytoskeleton protein that polymerizes to produce filaments (F-actin) that form crosslinked networks in the cytoplasm of cells. The controlled polymerization of monomeric actin (G-actin) into Factin and the subsequent depolymerization of F-actin play key roles in cell division, motility, and contraction (Fletcher and Mullins 2010). In neurons, actin polymerization is involved in fundamental neurobiological 
processes, the dynamic plasticity of dendritic spines, formation and motility of growth cones, and polarized cargo sorting at the axon initial segment (Konietzny et al. 2017).

Other proteins related to actin cytoskeleton formation were identified in the urano-proteome and are detailed below. One example is cellular non-muscle myosin-9, which appears to play a role in cytokinesis, cell shape, and specialized functions such as secretion and capping. During cell spreading, myosin- 9 fulfills an important function in cytoskeleton reorganization and has different roles in the regulation of the actin network (Betapudi 2010). Profilin-1 binds to actin and affects the structure of the cytoskeleton. It prevents the polymerization of actin at high concentrations but enhances it at low concentrations (Alkam et al. 2017). In neurons, profilin-1 maintains G/F-actin ratios together with capping proteins (Konietzny et al. 2017). Cofilin-1 binds to F-actin and exhibits $\mathrm{pH}$-sensitive F-actin depolymerizing activity. It regulates actin cytoskeleton dynamics and plays a role in the regulation of cell morphology and cytoskeletal organization. It is thus an important protein for normal progress through mitosis and normal cytokinesis (Bernstein and Bamburg 2010). In neurons, cofilin-1 modulates dendritic spine morphology and is involved in long-term potentiation through the enhancement of actin depolymerization in spines (Konietzny et al. 2017). Filamin-A promotes orthogonal branching of actin filaments, links actin filaments to membrane glycoproteins, anchors various transmembrane proteins to the actin cytoskeleton and serves as a scaffold for a wide range of cytoplasmic signaling proteins (Razinia et al. 2012). Vinculin, an F-actin-binding protein involved in cell-matrix adhesion and cell-cell adhesion (Le Clainche et al. 2010), as well as alpha-actinin-1 and -4, F-actin cross-linking proteins that are involved in neurons in dendrite elaboration and branching. Moesin and ezrin are probably involved in connections of major cytoskeletal structures to the plasma membrane. These proteins are mainly actin-binding proteins. These results suggest that the binding of $\mathrm{U}(\mathrm{VI})$ with several actin partners could have an impact on actin network regulation.

Based on the urano-proteome data, the top five diseases and biological disorders given by IPA analysis are endocrine system disorders, organismal injury and abnormalities, neurological disease, skeletal and muscular disorders, and psychological disorders (Table 1). Our proteomics results from a cellular model of U(VI) exposure are consistent with the reported effects of uranium on animal models. The United Nations Scientific Committee on the Effects of Atomic Radiations (UNSCEAR 2017) recently reviewed radiobiological and toxicological effects of exposure to $\mathrm{U}(\mathrm{VI})$. In terms of effects on the rat brain, brain toxicity leading to neurobehavioral impairments, associated with increased locomotor activity, as well as perturbation of the sleep-wake cycle, decreased memory, and increased anxiety were reported. The Committee mentioned that the mechanisms underlying these neurobehavioral disturbances are not clearly understood (UNSCEAR 2017).

\subsubsection{Most abundant common proteins}

To analyze the most abundant common proteins, the normalized spectral abundance factor (NSAF) was used (Zybailov et al. 2006). The NSAF represents the relative proportion of each protein in a sample and is used for quantitative proteomics. This value made it possible to select the most abundant $\mathrm{U}(\mathrm{VI})$-affine proteins for each analytical strategy.

The NSAFs were first calculated for each of the 269 common proteins to enable their ranking in two independent lists corresponding to the two chromatographic strategies. Then, the ten most abundant proteins common to the two populations were extracted from the NSAF ranking established from the SEC experiments because they correspond to $\mathrm{U}(\mathrm{VI})$-bound proteins in cellulo. Table 2 presents these proteins with some of their physicochemical characteristics, i.e., molecular weights, calculated isoelectric points, and their composition in some amino acids known to coordinate with $\mathrm{U}(\mathrm{VI})$ (both the oxygen of aspartate, glutamate, and tyrosinate and the nitrogen of histidine are hard Lewis bases). 
Table 2: The ten most abundant proteins from among the 269 common proteins were extracted from the NSAF ranking established from the SEC experiments. Their molecular weights and their calculated isoelectric points are shown, as are their calculated compositions in some amino acids. D: aspartate; E: glutamate; H: histidine; Y: tyrosine.

\begin{tabular}{|c|c|c|c|c|c|c|c|c|c|c|}
\hline \multirow[b]{2}{*}{ Accession } & \multirow[b]{2}{*}{ Description } & \multirow[b]{2}{*}{$\begin{array}{l}\mathrm{MW} \\
{[\mathrm{kDa}]}\end{array}$} & \multirow[b]{2}{*}{$\begin{array}{l}\text { calc. } \\
\text { pl }\end{array}$} & \multirow{2}{*}{$\begin{array}{c}\text { SEC } \\
\text { NSAF } \\
(\%)\end{array}$} & \multirow{2}{*}{$\begin{array}{c}\text { IMAC } \\
\text { NSAF } \\
(\%)\end{array}$} & \multicolumn{5}{|c|}{ Amino acid composition (\%) } \\
\hline & & & & & & D & $E$ & $\mathrm{H}$ & $\mathbf{Y}$ & $\mathrm{D}+\mathrm{E}+\mathrm{H}+\mathrm{Y}$ \\
\hline P62937 & $\begin{array}{l}\text { Peptidyl-prolyl cis-trans } \\
\text { isomerase A }\end{array}$ & 18.001 & 7.81 & 1.8 & 2.8 & 4.2 & 7.3 & 2.4 & 1.2 & 15.2 \\
\hline G3V1A4 & $\begin{array}{c}\text { Cofilin } 1 \text { (Non-muscle), isoform } \\
\text { CRA_a }\end{array}$ & 16.801 & 8.35 & 1.6 & 3.7 & 6.7 & 10.1 & 0.7 & 4.0 & 21.5 \\
\hline P04406 & $\begin{array}{c}\text { Glyceraldehyde-3-phosphate } \\
\text { dehydrogenase }\end{array}$ & 36.030 & 8.46 & 1.4 & 1.8 & 6.0 & 3.9 & 3.0 & 2.7 & 15.5 \\
\hline P13667 & Protein disulfide-isomerase A4 & 72.887 & 5.07 & 1.2 & 3.2 & 8.5 & 9.6 & 1.4 & 4.2 & 23.7 \\
\hline P62258 & 14-3-3 protein epsilon & 29.155 & 4.74 & 1.2 & 1.7 & 8.6 & 11.4 & 1.2 & 4.7 & 25.9 \\
\hline P23284 & $\begin{array}{l}\text { Peptidyl-prolyl cis-trans } \\
\text { isomerase B }\end{array}$ & 23.728 & 9.41 & 1.2 & 3.9 & 6.9 & 5.6 & 1.4 & 1.9 & 15.7 \\
\hline P60709 & Actin, cytoplasmic 1 & 41.710 & 5.48 & 1.1 & 1.6 & 6.1 & 6.9 & 2.4 & 4.0 & 19.5 \\
\hline P07737 & Profilin-1 & 15.045 & 8.27 & 1.1 & 1.8 & 6.4 & 2.9 & 1.4 & 3.6 & 14.3 \\
\hline A2A2D0 & Stathmin (Fragment) & 9.787 & 7.42 & 0.9 & 2.4 & 2.4 & 19.5 & 2.4 & 0.0 & 24.4 \\
\hline C9JFR7 & Cytochrome c (Fragment) & 11.326 & 9.66 & 0.8 & 3.6 & 3.0 & 6.9 & 3.0 & 5.9 & 18.8 \\
\hline
\end{tabular}

First of all, the NSAF values calculated for the proteins from the SEC strategy are smaller than those from the IMAC strategy, in keeping with IMAC selectivity. The molecular weights range from $9 \mathrm{kDa}$ (stathmin fragment) to $73 \mathrm{kDa}$ (protein disulfide-isomerase A4), i.e., rather small proteins. All of them were isolated both in fractions F1 and F3 of the SEC experiments, meaning that they are probably associated with other proteins in the F1 fraction. None of these ten proteins were eluted in the F2 fraction, indicating that the U(VI) proteins in the F2 fraction are less abundant taking into account their NSAFs (data not shown). The pI values indicate that $70 \%$ of these ten proteins were globally positively charged. As expected, they were isolated in the A1 fraction corresponding to the flow-through of the ion exchange step performed before the IMAC, the remaining $30 \%$ being isolated in the A2 and A3 fractions (data not shown).

Aspartate, glutamate, and tyrosine are hard Lewis bases that contain oxygen from carboxylates or phenolates and that are able to bind U(VI). The theoretical aspartate + glutamate + tyrosine + histidine frequency is around 17.4 in vertebrates (Bairoch). Interestingly, out of these ten selected proteins, six present higher frequencies up to 25.9. Furthermore, PDIA4 (P13667) presents two clusters of amino acids prone to U(VI) binding, one long cluster (ED EEEEEEEDDD EEEDDLE) in its N-terminal part and another small cluster (EP EEFDSD) in its Cterminal part. Such sequences are not evidenced in the nine remaining proteins. Nonetheless, profilin-1 (P07737) presents six phosphorylation sites, five of them on serine and one on tyrosine residues. Phosphorylations have been shown to reinforce the binding of $U(V I)$ to glutamate and aspartate. Even if it remains rather difficult to predict the $\mathrm{U}(\mathrm{VI})$ binding sites in proteins, our results are consistent with what is known about uranium coordination chemistry.

Apart from these preliminary considerations, this list of the ten most common proteins in the urano-proteome reveals some interesting information about the effects of U(VI). Peptidyl-prolyl cis-trans isomerase A (P62937) is the most abundant U(VI)-bound protein when SH-SY5Y cells are exposed to U(VI), and peptidyl-prolyl cistrans isomerase B (P23284) is also one of the ten proteins on the present list. Both of them accelerate the correct folding of proteins (Freedman et al. 2017; Schmidpeter and Schmid 2015). Furthermore, peptidyl-prolyl cis-trans isomerase B interacts with protein disulfide-isomerase A4, which is also on this list (Schonbrunner and Schmid 1992). Glyceraldehyde-3-phosphate dehydrogenase (P04406) is one of the enzymes of the main pathways presented above and is involved in glycogenesis. In addition, four of these ten proteins are actin and actinbinding proteins, all of them playing a crucial role in the regulation of the cytoskeleton (Pollard 2016; Schmitz and Bereiter-Hahn 2002). Two other proteins complete this selection: 14-3-3 protein epsilon and cytochrome c. Once bound to 14-3-3 protein epsilon, U(VI) may affect the ability of the former to regulate several signaling 
pathways. The presence of cytochrome $\mathrm{c}$ in the ten most abundant proteins of the urano-proteome reinforces previously published results on the potential role of cytochrome $\mathrm{c}$ in oxidative stress induced by uranium (Shaki et al. 2013). All of these results highlight how uranyl could affect this cell line at different levels of cell functions.

\section{Conclusions}

Advances in the description of metalloproteomes provide a better understanding of the mechanism and precise role of metalloproteins in the brain (Lothian et al. 2013). Because the brain is a sensitive target of U(VI), the aim of the present study was to identify $\mathrm{U}(\mathrm{VI})$ target proteins in neuronal cells exposed to non-toxic $\mathrm{U}(\mathrm{VI})$ concentrations. We crossed two complementary approaches, which is more relevant than using a single identification method, in order to isolate, identify, and characterize proteins capable of selectively binding U(VI) in neuron-like cell lysates. This strategy enabled the identification of 269 common U(VI)-affine proteins (the urano-proteome). Functional annotation and distribution into known cell functions and canonical pathways were performed thanks to Ingenuity Pathway Analysis software. Among these pathways, ubiquitination, glycolysis/gluconeogenesis, actin cytoskeleton signaling, and unfolded protein response were particularly highlighted by the presence of several U(VI)-affine proteins in each of them. Furthermore, a semi-quantitative analysis of these 269 proteins was performed to focus on the ten most abundant $\mathrm{U}(\mathrm{VI})$-affine proteins. Nine of them belong to these five canonical pathways, confirming that when neuronal cells are exposed to U(VI), these pathways could be disrupted, not only by the number of $\mathrm{U}(\mathrm{VI})$-affine proteins potentially altered in each pathway, but also by the particular abundance of some of them.

Although uranium has already been suggested to have an impact on the cytoskeleton, carbohydrate metabolism, protein ubiquitination, and oxidative stress, our study is the first to identify a large number of proteins from these metabolic pathways that are linked to an exposure to uranium in cellulo. These results pave the way for a better understanding of the mechanisms involved in the toxic effects of uranium. 


\section{FIGURE CAPTIONS}

Fig. 1: Experimental design of the analytical strategy.

Fig. 2: UV and q-ICP-MS chromatograms obtained for the lysates of SH-SY5Y cells exposed to $10 \mu \mathrm{M} \mathrm{U}(\mathrm{VI})$. The dashed rectangles indicate the three protein fractions collected.

Fig. 3: Venn diagram of the 269 common proteins.

Fig. 4: Cellular localization and protein function of the urano-proteome.

Fig. 5: Glycolysis pathway and U(VI)-bound enzymes. 


\section{REFERENCES}

Alkam D, Feldman EZ, Singh A, Kiaei M (2017) Profilin1 biology and its mutation, actin(g) in disease Cellular and molecular life sciences : CMLS 74:967-981 doi:10.1007/s00018-016-2372-1

Aryal BP, Paunesku T, Woloschak GE, He C, Jensen MP (2012) A proteomic approach to identification of plutonium-binding proteins in mammalian cells Journal of Proteomics 75:1505-1514 doi:10.1016/j.jprot.2011.11.023

ATSDR (2013) Toxicological profile for uranium U.S. DEPARTMENT OF HEALTH AND HUMAN SERVICES. https://www.atsdr.cdc.gov/toxprofiles/tp.asp?id=440\&tid=77. Accessed 2018/12/12

Bairoch A Release notes for UniProtKB/Swiss-Prot release 2013_04 - April 2013. https://web.expasy.org/protscale/pscale/A.A.Swiss-Prot.html. Accessed 2019/01/24

Banday AA, Priyamvada S, Farooq N, Yusufi AN, Khan F (2008) Effect of uranyl nitrate on enzymes of carbohydrate metabolism and brush border membrane in different kidney tissues Food Chem Toxicol 46:2080-2088 doi:10.1016/j.fct.2008.01.048

Barber DS et al. (2007) Neurological effects of acute uranium exposure with and without stress Neurotoxicology 28:1110-1119 doi:10.1016/j.neuro.2007.05.014

Basset C, Dedieu A, Guerin P, Quemeneur E, Meyer D, Vidaud C (2008) Specific capture of uranyl protein targets by metal affinity chromatography J Chromatogr A 1185:233-240 doi:10.1016/j.chroma.2008.01.081

Bensoussan $\mathrm{H}$ et al. (2009) Heavy metal uranium affects the brain cholinergic system in rat following sub-chronic and chronic exposure Toxicology 261:59-67 doi:10.1016/j.tox.2009.04.054

Bernstein BW, Bamburg JR (2010) ADF/cofilin: a functional node in cell biology Trends in cell biology 20:187-195 doi:10.1016/j.tcb.2010.01.001

Betapudi V (2010) Myosin II motor proteins with different functions determine the fate of lamellipodia extension during cell spreading PloS one 5:e8560-e8560 doi:10.1371/journal.pone.0008560

Bishop DP, Hare DJ, Clases D, Doble PA (2018) Applications of liquid chromatography-inductively coupled plasma-mass spectrometry in the biosciences: A tutorial review and recent developments Trac-Trend Anal Chem 104:11-21 doi:10.1016/j.trac.2017.09.017

Bussy C, Lestaevel P, Dhieux B, Amourette C, Paquet F, Gourmelon P, Houpert P (2006) Chronic ingestion of uranyl nitrate perturbs acetylcholinesterase activity and monoamine metabolism in male rat brain Neurotoxicology 27:245-252 doi:10.1016/j.neuro.2005.11.003

Carmona A et al. (2018) Uranium exposure of human dopaminergic cells results in low cytotoxicity, accumulation within sub-cytoplasmic regions, and down regulation of MAO-B Neurotoxicology 68:177-188 doi:10.1016/j.neuro.2018.07.019

Chaudhury A, Chander P, Howe PH (2010) Heterogeneous nuclear ribonucleoproteins (hnRNPs) in cellular processes: Focus on hnRNP E1's multifunctional regulatory roles RNA (New York, NY) 16:1449-1462 doi:10.1261/rna.2254110

Dedieu A, Berenguer F, Basset C, Prat O, Quemeneur E, Pible O, Vidaud C (2009) Identification of uranyl binding proteins from human kidney-2 cell extracts by immobilized uranyl affinity chromatography and mass spectrometry J Chromatogr A 1216:5365-5376 doi:10.1016/j.chroma.2009.05.023

Dinocourt C, Legrand M, Dublineau I, Lestaevel P (2015) The neurotoxicology of uranium Toxicology 337:58-71 doi:10.1016/j.tox.2015.08.004

Eb-Levadoux Y, Frelon S, Simon O, Arnaudguilhem C, Lobinski R, Mounicou S (2017) In vivo identification of potential uranium protein targets in zebrafish ovaries after chronic waterborne exposure Metallomics 9:525-534 doi:10.1039/c6mt00291a

Fletcher DA, Mullins RD (2010) Cell mechanics and the cytoskeleton Nature 463:485-492 doi:10.1038/nature08908 
Freedman RB et al. (2017) 'Something in the way she moves': The functional significance of flexibility in the multiple roles of protein disulfide isomerase (PDI) Biochim Biophys Acta Proteins Proteom 1865:1383-1394 doi:10.1016/j.bbapap.2017.08.014

Han Siew P, Tang Yue H, Smith R (2010) Functional diversity of the hnRNPs: past, present and perspectives Biochemical Journal 430:379-392 doi:10.1042/bj20100396

Konietzny A, Bar J, Mikhaylova M (2017) Dendritic Actin Cytoskeleton: Structure, Functions, and Regulations Front Cell Neurosci 11:147 doi:10.3389/fncel.2017.00147

Le Clainche C, Dwivedi SP, Didry D, Carlier M-F (2010) Vinculin is a dually regulated actin filament barbed end-capping and side-binding protein The Journal of biological chemistry 285:2342023432 doi:10.1074/jbc.M110.102830

Lothian A, Hare DJ, Grimm R, Ryan TM, Masters CL, Roberts BR (2013) Metalloproteomics: principles, challenges, and applications to neurodegeneration Front Aging Neurosci 5 doi:10.3389/fnagi.2013.00035

Malard V, Prat O, Darrouzet E, Berenguer F, Sage N, Quemeneur E (2005) Proteomic analysis of the response of human lung cells to uranium Proteomics 5:4568-4580

McDiarmid MA et al. (2000) Health effects of depleted uranium on exposed Gulf War veterans Environ Res 82:168-180 doi:10.1006/enrs.1999.4012

Mergenthaler P, Lindauer U, Dienel GA, Meisel A (2013) Sugar for the brain: the role of glucose in physiological and pathological brain function Trends Neurosci 36:587-597 doi:10.1016/j.tins.2013.07.001

Michalke B, Willkommen D, Drobyshev E, Solovyev N (2018) The importance of speciation analysis in neurodegeneration research Trac-Trend Anal Chem 104:160-170 doi:10.1016/j.trac.2017.08.008

Paredes E et al. (2018) A new procedure for high precision isotope ratio determinations of $\mathrm{U}, \mathrm{Cu}$ and $\mathrm{Zn}$ at nanogram levels in cultured human cells: What are the limiting factors? Talanta 178:894-904 doi:https://doi.org/10.1016/j.talanta.2017.10.046

Paredes E et al. (2016) Evidence of isotopic fractionation of natural uranium in cultured human cells $P$ Natl Acad Sci USA 113:14007-14012 doi:10.1073/pnas.1610885113

Pible O, Guilbaud P, Pellequer JL, Vidaud C, Quemeneur E (2006) Structural insights into proteinuranyl interaction: towards an in silico detection method Biochimie 88:1631-1638 doi:10.1016/j.biochi.2006.05.015

Pollard TD (2016) Actin and Actin-Binding Proteins Cold Spring Harb Perspect Biol 8 doi:10.1101/cshperspect.a018226

Porath J, Carlsson J, Olsson I, Belfrage G (1975) Metal chelate affinity chromatography, a new approach to protein fractionation Nature 258:598-599

Prat O, Berenguer F, Malard V, Tavan E, Sage N, Steinmetz G, Quemeneur E (2005) Transcriptomic and proteomic responses of human renal HEK293 cells to uranium toxicity Proteomics 5:297306 doi:10.1002/pmic.200490085

Presgraves SP, Ahmed T, Borwege S, Joyce JN (2004) Terminally differentiated SH-SY5Y cells provide a model system for studying neuroprotective effects of dopamine agonists Neurotox Res 5:579-598

Razinia Z, Mäkelä T, Ylänne J, Calderwood DA (2012) Filamins in mechanosensing and signaling Annual review of biophysics 41:227-246 doi:10.1146/annurev-biophys-050511-102252

Renault S, Faiz H, Gadet R, Ferrier B, Martin G, Baverel G, Conjard-Duplany A (2010) Uranyl nitrate inhibits lactate gluconeogenesis in isolated human and mouse renal proximal tubules: a 13CNMR study Toxicol Appl Pharmacol 242:9-17 doi:10.1016/j.taap.2009.09.002

Schmidpeter PA, Schmid FX (2015) Prolyl isomerization and its catalysis in protein folding and protein function J Mol Biol 427:1609-1631 doi:10.1016/j.jmb.2015.01.023

Schmitz HD, Bereiter-Hahn J (2002) Glyceraldehyde-3-phosphate dehydrogenase associates with actin filaments in serum deprived NIH 3 T3 cells only Cell Biol Int 26:155-164 doi:10.1006/cbir.2001.0819 
Schonbrunner ER, Schmid FX (1992) Peptidyl-prolyl cis-trans isomerase improves the efficiency of protein disulfide isomerase as a catalyst of protein folding Proc Natl Acad Sci U S A 89:45104513 doi:10.1073/pnas.89.10.4510

Shaki F, Hosseini MJ, Ghazi-Khansari M, Pourahmad J (2013) Depleted uranium induces disruption of energy homeostasis and oxidative stress in isolated rat brain mitochondria Metallomics 5:736-744 doi:10.1039/c3mt00019b

Szpunar J, Lobinski R (2002) Multidimensional approaches in biochemical speciation analysis Anal Bioanal Chem 373:404-411 doi:10.1007/s00216-002-1282-2

Tai H-C, Besche H, Goldberg A, Schuman E (2010) Characterization of the brain 26 S proteasome and its interacting proteins Frontiers in Molecular Neuroscience 3 doi:10.3389/fnmol.2010.00012

Templeton DM, Fujishiro H (2017) Terminology of elemental speciation - An IUPAC perspective Coordin Chem Rev 352:424-431 doi:10.1016/j.ccr.2017.02.002

UNSCEAR (2017) Sources, effects and risks of ionizing radiation. United Nations. http://www.unscear.org/unscear/en/publications/2016.html. Accessed 2018/12/12

Zybailov B, Mosley AL, Sardiu ME, Coleman MK, Florens L, Washburn MP (2006) Statistical analysis of membrane proteome expression changes in Saccharomyces cerevisiae J Proteome Res 5:2339-2347 doi:10.1021/pr060161n 